\title{
A valorização da espiritualidade nas práticas de educação popular em saúde desenvolvidas na atenção básica
}

\author{
DOI: 10.3395/reciis.v4i3.389pt
}

\section{Patrícia Serpa de Souza Batista}

Professor Assistente do Departamento de Enfermagem Clínica da Universidade Federal da Paraíba, João Pessoa, Paraíba, Brasil

patriciaserpa@oi.com.br

\begin{abstract}
Resumo
Este artigo visa evidenciar a valorização da espiritualidade nas práticas de educação popular em saúde desenvolvidas na atenção básica. O trabalho com a saúde desenvolvido na atenção básica deve considerar o indivíduo em sua essência, como um ser que tem necessidades no âmbito biológico, no psicológico, no social e no espiritual, as quais precisam ser percebidas e cuidadas. A ação educativa, norteada pela educação popular, favorece ao encontro com essa dimensão sutil que é a espiritualidade, pois é desenvolvida com base em princípios que envolvem o fortalecimento de vínculos, a relação dialogada, a escuta sensível, a solidariedade, a afetividade, a valorização da dignidade humana, entre outros. Em momentos de dor e de sofrimento, a valorização da espiritualidade pode ser extremamente transformadora, conduzindo o doente e seus familiares a renovarem o ânimo e a buscar novas formas de enfrentamento da realidade desafiadora que estejam vivenciando. Conclui-se, entre outros aspectos, que esse é um tema ainda pouco debatido na formação universitária em saúde. Sugere-se que as academias priorizem a temática espiritualidade em seus currículos, permitindo ao futuro profissional adquirir uma maior amplitude de conhecimentos, com vistas a melhor se preparar para a prática cotidiana do cuidar, no contexto da atenção básica.
\end{abstract}

\section{Palavras-chave}

saúde coletiva; atenção básica; aaúde da família; espiritualidade; educação popular em saúde
Tradicionalmente, crenças e experiências espirituais têm sido um dos componentes marcantes em diversas sociedades. Nesse contexto, a população em geral, profissionais de saúde e pesquisadores têm reconhecido a importância da dimensão espiritual para a saúde. Entretanto, embora o desenvolvimento de pesquisas que envolvem esse tema tenha avançado, principalmente nas últimas décadas, há, ainda, uma deficiência na consolidação de uma revisão abrangente da literatura, em português, que seja acessível a pesquisadores e a clínicos (MOREIRA-ALMEIDA, 2007).

É notória a presença da espiritualidade na área da saúde. Mesmo com a ênfase no aspecto biológico e na medicalização, que o paradigma cartesiano ainda hegemônico impõe aos profissionais da saúde, a valorização da dimensão espiritual e da religiosidade se faz presente no cuidado desenvolvido por profissionais dessa área, em face dos mais diversos problemas de saúde e de situações de risco que são enfrentados cotidianamente pela população.

Ainda vivenciamos um sistema de saúde muito marcado pelo modelo biomédico de atenção à saúde, que se caracteriza, segundo Capra (2001), por uma concepção mecanicista e fragmentada do corpo humano, em que a doença é vista como um mau funcionamento de uma das partes dessa máquina, que precisa ser consertada pelo 
médico. Esse modelo constitui o alicerce conceitual da moderna medicina científica, como resultado da influência do paradigma cartesiano no pensamento médico.

Conforme Capra (2001), o paradigma cartesiano é pautado na filosofia de Descartes (Século XVII), a qual, com sua "rigorosa divisão entre corpo e mente, levou os médicos a se concentrarem na máquina corporal e a negligenciarem os aspectos psicológicos, sociais e ambientais da doença". $\mathrm{O}$ autor acrescenta que o avanço da moderna medicina científica teve início no Século XIX, através dos grandes progressos da Biologia que foram acompanhados pelo avanço da tecnologia na área médica. Esse fato levou os médicos a gradualmente transferirem a atenção do doente para a doença, transformando os hospitais em centros de diagnóstico, terapia e ensino.

Ao se reportar à racionalidade da Biomedicina, Camargo Júnior (2003) enfatiza que ela prioriza o biológico em detrimento dos aspectos subjetivos que podem envolver o processo de adoecimento. Fazem parte dessa racionalidade elementos como o processo de fragmentação do corpo humano, com um crescente número de especialidades, ganhos tecnológicos mais avançados e o fato de ser voltada para a cura através da utilização acentuada de medicamentos e cirurgias, entre outros.

O modelo da Biomedicina começou a perder força nos países desenvolvidos, principalmente a partir da segunda metade do Século $X X$, devido ao caráter fragmentado e ineficiente da assistência à saúde direcionada, sobretudo, ao tratamento das doenças crônico-degenerativas, como também em decorrência do alto custo envolvido no processo, gerando grande insatisfação na população. Tal situação contribuiu para a busca pelas terapias alternativas, como a homeopatia, a acupuntura e os florais. Contribuiu também para o desenvolvimento de estudos relacionados a aspectos sociais e subjetivos que influenciam no processo de adoecimento e de cura, bem como estratégias de saúde integradas a uma visão religiosa (VASCONCELOS, 2006).

Nesse sentido, verifica-se, no campo da saúde coletiva, a emergência de novas abordagens para se pensar o adoecimento, tais como: a integralidade das ações de saúde, a humanização do atendimento e a produção do cuidado, com vistas à transformação do modelo tecnoassistencial. Observa-se também uma crescente aceitação da medicina alternativa pela população, na qual os aspectos psíquicos e físicos são indissociáveis na busca do restabelecimento do equilíbrio (GUEDES et al., 2006).

No cuidado em saúde desenvolvido na atenção básica, o Ministério da Saúde prioriza o desenvolvimento de ações através da estratégia de Saúde da Família, que atua numa concepção de superação da antiga proposição de caráter exclusivamente centrado na doença, desenvolvendo-se por meio de práticas gerenciais e sanitárias, democráticas e participativas, sob a forma de trabalho em equipe dirigido às populações de territórios delimitados (BRASIL, 2004).

As Equipes de Saúde da Família (médicos, enfermeiros, auxiliares de enfermagem, agentes comunitários de saúde, dentistas e auxiliares de consultório dentário) atuam, principalmente, na unidade de saúde ou nos domićlios. Essa equipe e a população acompanhada criam vínculos de responsabilização, o que facilita a identificação, o atendimento, o acompanhamento dos agravos à saúde e a realização das atividades educativas voltadas à prevenção de doenças e à promoção da saúde (BRASIL, 2006).

As ações educativas são uma prioridade no cuidado desenvolvido na atenção básica. Nesse contexto, destacase a metodologia da educação popular em saúde, voltada para o desenvolvimento de uma ação pedagógica direcionada ao ser humano inserido em seu contexto de vida. Vasconcelos (1997) esclarece que a educação popular trabalha pedagogicamente o homem e os grupos envolvidos no processo de participação popular, através de formas coletivas de aprendizado e de investigação, promovendo a análise crítica sobre a realidade e as estratégias de luta e de enfrentamento.

Cabe destacar que, atualmente, há um processo de institucionalização da educação popular em saúde nas práticas desenvolvidas na atenção básica, mediante a estratégia de Saúde da Família. Em junho de 2009, o ministro da saúde, José Gomes Temporão, instituiu o Comitê Nacional de Educação Popular em Saúde (CNEPS), com objetivos voltados ao fortalecimento da luta pelo direito à saúde e em defesa do Sistema Único de Saúde, como também direcionados à construção de bases pedagógicas para a transformação das práticas de educação em saúde desenvolvidas, fortalecendo a autonomia da população e a relação fraterna e solidária entre gestores, profissionais e usuários dos serviços de saúde (BRASIL, 2009).

A educação popular em saúde encontra-se vinculada à problematização da realidade vivenciada pela população, a fim de buscar melhores condições de vida e de saúde, e mediada pelo diálogo, pela valorização do saber popular, pela construção da conscientização e da autonomia do indivíduo e da coletividade. Essa forma de educar pode ser percebida como um modelo alternativo ao paradigma 
biomédico, ainda hegemônico na atualidade. Se, por um lado, muitos profissionais de saúde ainda continuam realizando práticas em saúde voltadas para a doença, para a terapia medicamentosa e para a cura propriamente dita, outros se identificam e trabalham nos moldes da educação popular, numa abordagem em saúde mais voltada ao paradigma da medicina integral, que visualiza o ser humano em sua totalidade, ou seja, em seus aspectos biopsicossociocultural e espiritual, inserido em seu contexto de vida, com todas as suas crenças, valores e características, que precisam ser valorizados em uma conduta terapêutica multiprofissional.

Nesse sentido, ressalta-se a relevância da presença da espiritualidade no trabalho em saúde realizado com enfoque na metodologia da educação popular em saúde, visto que a espiritualidade, como refere Vasconcelos (2004), é uma força capaz de auxiliar o indivíduo, a família e a comunidade, a melhor superar as dificuldades da vida, como também as doenças que vivenciam, proporcionando um melhor enfrentamento da realidade cotidiana.

Para Boff (2001), a espiritualidade é uma das fontes primordiais de inspiração do novo, de esperança e de autotranscendência do ser humano. Segundo o autor, na atualidade, "a espiritualidade vem sendo descoberta como dimensão profunda do humano, como elemento necessário para o desabrochar pleno de nossa individuação e como espaço de paz no meio dos conflitos e das desolações sociais e existenciais".

Nesse sentido, motivamo-nos a desenvolver este estudo, que visa evidenciar a valorização da espiritualidade nas práticas de educação popular em saúde desenvolvidas na atenção básica.

Este trabalho envolve um tema bastante complexo, porém busca contribuir, principalmente, para um repensar da prática cotidiana dos profissionais de saúde inseridos na atenção básica, visto que reflete sobre aspectos relacionados à subjetividade humana no processo de adoecimento e de cura. Além disso, pretende contribuir com as discussões acerca dessa temática, no âmbito acadêmico, e suscitar o desenvolvimento de novos trabalhos nessa direção.

A seguir, serão feitas algumas considerações pertinentes à temática em estudo.

\section{A espiritualidade e a religião}

Embora as palavras espiritualidade e a religião muitas vezes sejam compreendidas como sinônimo, elas comportam significados diferenciados. O dicionário define espiritualidade como aquilo que é relativo ao espírito, a parte imaterial do ser humano, inteligência, pensamento, ideia. Já a palavra religião é definida como crença na existência de uma força ou de forças sobrenaturais, manifestação de tal crença por meio de doutrina e ritual próprios, reverência às coisas sagradas; devoção, fé, culto, posição filosófica (FERREIRA, 2006a). Para Dalai-Lama (apud BOFF, 2001), a religião está relacionada com a crença no direito à salvação, pregada por qualquer tradição de fé, associada a ensinamentos ou dogmas religiosos, rituais, orações.

A espiritualidade, portanto, não está relacionada a uma profissão de fé específica, a uma doutrina que contenha rituais próprios, mas diz respeito à própria essência do ser humano. Para Leloup e Hennezel (2003), a espiritualidade faz parte da constituição de todos os homens, independente de qualquer experiência religiosa.

As religiões constituem uma construção do ser humano que trabalha com o divino, com o sagrado, são caminhos institucionais capazes de ajudar a desenvolver a espiritualidade das pessoas; nasceram da espiritualidade, mas não são, em sua essência, o espiritual. A espiritualidade é uma dimensão de cada ser humano. Essa dimensão espiritual que cada pessoa detém se revela pela capacidade de diálogo consigo mesmo, com o próprio coração, traduzindo-se "pelo amor, pela sensibilidade, pela compaixão, pela escuta ao outro, pela responsabilidade e pelo cuidado como atitude fundamental" (BOFF, 2001). Espiritualidade implica todo esse conjunto de relações. No ser humano, é a capacidade de transformar os fatos em uma experiência de libertação, em um projeto, em uma prática em defesa da vida, de sua sacralidade, protestando contra todos os mecanismos de morte, em todas as circunstâncias (BOFF, 1997).

Atualmente, convive-se com uma crescente busca da população pelo desenvolvimento da espiritualidade e da religiosidade. Esse aspecto é atribuído por Soares et al. (2005) à necessidade de aliviar o sofrimento e de buscar a cura. Segundo Valla (1998), há uma procura das classes populares por todas as religiões. Essa procura é explicada, principalmente, pelos problemas causados pelo crescimento da urbanização, pelo aumento das necessidades individuais e coletivas e pela dilapidação dos direitos sociais e humanos. A prática da religião pelas classes populares contribui para amenizar o sofrimento, aliviar as angústias das pessoas e é associada ao processo saúde-doença e à cura. A religião renova as forças para os embates cotidianos na luta pela sobrevivência.

Ao se reportar aos benefícios da fé no organismo das pessoas, Pereira (2002) afirma que estudos científicos 
revelam que, ao receber estímulos provocados pela meditação, pela oração ou pela leitura de um texto religioso, o corpo produz substâncias com efeitos analgésicos, como também provoca relaxamento dos músculos e sensação de serenidade. Esses efeitos, com certeza, influenciam, de maneira positiva, no enfrentamento de dificuldades da vida, de doenças crônicas, ou mesmo de situações que envolvem a morte e o morrer.

Segundo Pessini (2004), a fé e a oração favorecem um ambiente saudável, tanto em nível pessoal quanto social. No âmbito pessoal, a fé e a oração proporcionam um encontro consigo próprio, com as forças íntimas do espírito em sua luta pela sobrevivência, como também favorecem um momento de paz durante as tribulações da vida e as limitações que, por exemplo, uma doença crônica possa trazer. No âmbito social, a fé e a oração produzem uma ligação de amor e de solidariedade com os outros. Um momento de comunhão intensa em que cada ser se reabastece das energias salutares veiculadas pelo outro. Assim, todos se sentem fortalecidos, apoiados intimamente. Tudo isso gera saúde, esperança e ânimo contínuos, como também sensação de serenidade, de calma. Nos momentos mais angustiantes e turbulentos da vida, na presença da doença ou mesmo da morte, a oração acalma e faz o organismo se equilibrar.

No meio popular, o trabalho em saúde enfrenta problemas complexos. Há problemas de saúde que podem ser desencadeados por situações de violência, de abandono, de fome, de convivência com as drogas etc. Vasconcelos (2006) explica que a razão, muitas vezes, é insuficiente para lidar com toda essa complexidade, exigindo do profissional atitudes que envolvem também dimensões mais sutis do ser humano, como a dimensão espiritual, expressa através da percepção dos sentidos (sensação), da sensibilidade dos sentimentos (emoção), como também do uso da intuição, como forma de avaliar e pressentir a forma de atuar em cada situação específica.

A ação educativa, norteada pela educação popular, favorece o encontro com essa dimensão sutil da espiritualidade, pois é desenvolvida com base em princípios que envolvem o fortalecimento de vínculos, a relação dialogada, a escuta sensível, a valorização do saber popular, a solidariedade, a valorização da dignidade humana, entre outros. Em momentos de dor e de sofrimento, a valorização da espiritualidade, nessa forma de educar, pode ser extremamente transformadora e conduzir o doente e seus familiares a renovarem o ânimo e a buscarem novas formas de enfrentamento da realidade desafiadora que estejam vivenciando.
A valorização da espiritualidade nas práticas de educação popular em saúde desenvolvidas na atenção básica

No Brasil, a educação popular, desde a sua origem, esteve muito ligada ao campo religioso (VASCONCELOS, 2006). Essa educação, sistematizada por Paulo Freire, começa a ganhar notoriedade no país, a partir da década de 1960, estando ligada a movimentos como o Movimento de Educação de Base (MEB), por exemplo, articulado à Igreja Católica, que tinha objetivos voltados à alfabetização de adultos e a sua conscientização. O MEB deveria fundamentalmente oferecer uma educação que levasse o homem a se tornar consciente de seus valores físicos, espirituais e morais, valorizando a sua conduta na vida pessoal, familiar e social (PAIVA, 2003). Com o golpe militar de 1964, os movimentos de educação popular foram considerados subversivos e impedidos de serem executados. Entretanto, a partir dos anos 1970, a educação popular volta a se articular com maior força, principalmente vinculada à força progressista da igreja católica. Nesse período, profissionais de saúde, insatisfeitos com as suas práticas educativas de caráter, em geral, impositivo, normatizador e direcionadas para a mudança de comportamento, começam a se voltar para os aspectos teórico-metodológicos da educação popular, trazendo para o trabalho em saúde - desenvolvido, principalmente, no contexto das classes populares, aspectos condizentes com uma educação problematizadora, procurando, a partir de uma relação dialogada, prevenir doenças, promover saúde para a população, bem como apoiá-la na luta por melhores condições de vida. Na educação popular, o vocábulo popular refere-se ao projeto político que orienta sua proposta pedagógica, em busca de construir uma sociedade mais participativa, justa e igualitária (VASCONCELOS, 2001).

No campo da saúde, a educação popular atua como estratégia de superação da grande distância que existe entre o serviço de saúde e o saber científico, de um lado e, de outro, a dinâmica que envolve o adoecimento e a cura. A educação popular em saúde realiza ações que envolvem as dimensões do diálogo, do respeito e da valorização do saber popular. É considerada um instrumento de construção para uma saúde mais integral e adequada à vida da população (VASCONCELOS, 2006).

Nas Unidades de Saúde da Família, inseridos no ambiente físico e cultural onde mora cada família, a convivência diária dos profissionais com os moradores tende a ir mostrando "a ineficácia do modelo da Biomedicina em modificar a 
dinâmica de adoecimento e da cura. Os profissionais vão sendo desafiados a experimentar práticas de educação em saúde, passando a se assustar com a complexidade desse tipo de intervenção" (VASCONCELOS, 2006).

Na educação popular em saúde, os profissionais trabalham com o universo de significados, de crenças e de valores apreendidos na comunidade, como também convivem com a espiritualidade e a religiosidade que fazem parte da população. Dentro dessa perspectiva, esses profissionais devem agir relacionando-se efetivamente com a população, refletindo sobre o cotidiano das pessoas, considerando o conhecimento popular, a escuta, o diálogo e os sentimentos dos indivíduos que estão sendo cuidados.

As práticas de educação popular em saúde são realizadas, principalmente, na Unidade Saúde da Família, durante as visitas domiciliares e através das atividades coletivas, que são desenvolvidas, por exemplo, com idosos, gestantes e envolvem a participação de profissionais de saúde, população adscrita, estudantes universitários, lideranças comunitárias, entre outros.

No âmbito da atenção básica, os profissionais de saúde têm contato com pessoas portadoras dos mais diversos problemas. A doença crônica, o alcoolismo, o envolvimento com as drogas e o narcotráfico, o envelhecimento, a solidão e a possibilidade de finitude são exemplos de situações vivenciadas pelo ser humano que o levam a buscar um encontro consigo mesmo, com a sua espiritualidade, a fim de encontrar forças para superar, por exemplo, a doença, a solidão e o temor da morte, libertando-se, numa atitude de transcendência. Para Boff (2000), a transcendência diz respeito à capacidade de romper limites, de superar, projetarse sempre num mais além.

Em estudo sobre a vivência da espiritualidade, realizado com mulheres na fase do climatério, Sousa e Batista (2006) evidenciaram, entre outros aspectos, que a espiritualidade é considerada um apoio em suas vidas. É através do desenvolvimento da espiritualidade que elas encontram apoio para o enfrentamento cotidiano da solidão e da tristeza, o que gera amadurecimento para uma vida interior, aceitação das perdas de entes queridos, da saída dos filhos de casa, de seu envelhecimento, da doença e, até mesmo, de sua finitude.

Vale ressaltar que, no trabalho em saúde, norteado pela educação popular, a convivência intensa de profissionais de saúde com as classes populares tem significado um modo de construir vínculos emocionais, afetivos, com que a população se identifica, gerando um estado de alma aberto que acolhe a pessoa que necessita de cuidados, numa atitude ética que envolve respeito, amorosidade, diálogo, intuição e emoção.

A valorização da espiritualidade, no contexto da educação popular em saúde, contempla a prática do diálogo como componente essencial. É através do diálogo mediado por palavras significativas, por gestos como o sorriso ou o abraço, e até por momentos de silêncio, que a relação de intersubjetividade, de compreensão e de ligação profunda com o eu do outro se estabelece, firmando uma comunicação, através de fios invisíveis, que demonstram um contato que extrapola a dimensão física e emocional, trazendo paz e serenidade para os momentos de dor ou de conturbação experienciados. Segundo Freire (2005), quando o diálogo é fundamentado no amor, na humildade e na fé nos homens, faz-se uma relação horizontal, em que a confiança mútua é uma consequência óbvia, que gera esperança e transformação. É dentro dessa dimensão que os profissionais envolvidos na educação popular procuram vivenciar a transformação social, acolhendo o indivíduo, respeitando-o em sua autonomia e valorizando-o como cidadão.

Ao se reportar à espiritualidade na atenção primária à saúde, Smeke (2006) descreve que, na prática cotidiana de cuidar, quer seja na consulta, no grupo ou no domicílio, muitas vezes, os profissionais deparam-se com um emaranhado de queixas, dores, carências que se confundem e extravasam os limites da doença. Nesse momento, o sofrimento extrapola, claramente, a relação orgânica e, "se quisermos realmente ajudar, sairemos de nosso papel profissional e devemos colocar em ação o nosso lado humano". A autora refere que o desenvolvimento de ações com sensibilidade, perspicácia, intuição, interação, por vezes, têm o poder de aliviar muito mais do que grande parte das medicações em uso. É quando o profissional entra em contato com a dimensão que extrapola o espaço somatopsíquico do ser que está sendo cuidado e, através da escuta qualificada, do ato de acolher, gera compreensão, esperança, alívio da dor e do sofrimento.

A dimensão da espiritualidade também está relacionada ao trabalho que abrange a saúde mental. Segundo Koenig (2007), desde a década de 1990, investigações passaram a demonstrar que indivíduos com fé religiosa pareciam enfrentar melhor os estresses da vida, recuperar-se mais rapidamente da depressão, como também apresentar menor ansiedade que pessoas menos religiosas. Nesse sentido, é oportuno destacar a experiência de uma discente, durante sua participação em um projeto de extensão universitária norteado pela educação popular em saúde. Nesse relato, a então estudante Ferreira (2006b), sinaliza para a importância 
da espiritualidade e da religiosidade no cuidado que dedicava a uma jovem que tinha problemas mentais. A autora descreve que, no início de suas visitas a essa família, a jovem sempre se mantinha distante, desajeitada e com os cabelos despenteados. Em uma ocasião, durante a visita, fez uma oração mental, suplicando a Deus que a iluminasse para saber como agir diante daquela situação. Naquele instante, sentiu a necessidade de fazer um agrado à adolescente e decidiu pentear, com muito amor, os cabelos daquela jovem tão deprimida. Esse "momento mágico" tornou a garota mais receptiva aos seus cuidados e as visitas semanais subsequentes mais satisfatórias. Relata, ainda, a autora, que ela e a família tinham semelhança na religiosidade e que, muitas vezes, orou junto com aquela família, principalmente pela saúde de seus membros. Finalizando, afirma ter descoberto que deve utilizar-se da dimensão da espiritualidade no futuro exercício de sua profissão, pois a prática profissional e a fé têm em comum a promoção da vida, tornando o trabalho em saúde mais alegre a fecundo.

Em relação a esse relato, é importante ressaltar que o fato de a estudante ter sabido que ela e aquela família seguiam a mesma religião foi imprescindível para que se sentisse à vontade para orar com eles. Koenig (2005) afirma que a identificação da história espiritual da pessoa em cuidado é um dos aspectos fundamentais a ser realizado pelos profissionais de saúde, uma vez que lhe permite familiarizar-se com as crenças do indivíduo, entender o papel que a religião tem ao lidar com a doença, e ainda, proporcionar informação sobre o apoio espiritual que essa pessoa recebe dentro da comunidade e que pode ajudar em seu tratamento. Além disso, permite que o profissional tenha uma aproximação maior com essa pessoa, e até ore com ela, caso tenha a mesma formação religiosa e sinta necessidade de fazê-lo.

Outro aspecto que merece destaque diz respeito a situações que envolvem o cuidar de pessoas em estado terminal de vida. Nessas situações, é muito importante a prática educativa do profissional, auxiliando, através do diálogo e da escuta, no processo de aceitação da doença, minimizando medos, procurando dar apoio e conforto ao indivíduo e à família através da visita domiciliar. Nesses momentos, em que a cura do corpo não é mais alcançável, Huf (2002) destaca a importância do resgate da espiritualidade como um meio de transformar os momentos de angústia, através do respeito às crenças da pessoa, priorizando a busca pela paz interior com o objetivo de promover o bem-estar, apesar da inevitabilidade do sofrimento. A autora considera que vivenciar a espiritualidade inclui exercitar a fé, a esperança, o altruísmo e a solidariedade, aceitando a finitude como uma experiência que propicia sensibilizar-se com o outro e encontrar um significado para sua própria existência.

Assim, o profissional de saúde precisa proporcionar um cuidado ao ser humano numa perspectiva holística, valorizando o apoio espiritual, visando a que ele possa vivenciar momentos difíceis com serenidade. Conforme Leloup et al. (2003), espiritualidade é dar um "passo a mais" na aceitação dos próprios limites, como também diante do sofrimento, e ser solidário com quem necessita. É, simplesmente, na situação em que se está, dar esse "passo a mais" e ajudar o outro a fazer a mesma coisa diante de suas dificuldades.

Um elemento que merece destaque diz respeito a situações com que o profissional de saúde na atenção básica se depara e que é considerada como de sofrimento difuso. São queixas vagas e pouco definidas de usuários, compostas por dor, medo, ansiedade, mal-estar etc. Esses sintomas difusos geralmente não se enquadram em uma categoria diagnóstica precisa e parecem não ter origem orgânica. As classes populares denominam essa situação de doença dos nervos (VALLA, 2006). Segundo esse autor, na maioria das vezes esses sintomas são provenientes de diversos fatores, tais como: extremas dificuldades socioeconômicas, exposição a situações de violência, de insegurança, de falta de emprego, que provocam certa desordem física e psíquica, gerando sintomas inespecíficos.

Nesse sentido, Valla (2006), destaca o apoio social, em especial, a religiosidade, como caminho procurado por essas pessoas, em busca de um estado mental diferente que vislumbre saídas e enfrentamentos mais eficazes para os problemas que vivenciam cotidianamente. O apoio social diz respeito a quando as pessoas sentem que podem contar com o apoio de amigos, vizinhos, da família, da igreja e dos profissionais de saúde. Esse apoio causa melhoria na vida das pessoas. Portanto, os profissionais de saúde orientados pela educação popular devem estimular os indivíduos a aumentarem sua rede social e, nesse sentido, devem apoiar, indistintamente, a prática da religiosidade em seu trabalho educativo.

Cabe acrescentar que, na educação popular, os profissionais também trabalham com lideranças e movimentos sociais. Nesse espaço, a espiritualidade, a arte e o saber de tornar o viver orientado pela experiência da transcendência também são fundamentais. Essas pessoas afirmam que encontram na sua religiosidade a fonte de ânimo, de motivação para seguirem empenhando-se em suas lutas coletivas, em busca de uma vida mais digna e feliz. Ademais, buscam no estado alterado de consciência que a 
espiritualidade propicia percepções simbólicas que ajudam a compreender a complexidade das situações que vivenciam e a construir orientações e sentidos para suas lutas políticas (VASCONCELOS, 2006).

Assim, a valorização da espiritualidade, nas práticas de educação popular em saúde desenvolvidas na atenção básica, envolve a vivência em situações as mais diversas, compartilhadas com a população que faz parte daquele território. Essas práticas possibilitam uma maior aproximação entre os profissionais de saúde e as pessoas que estão sendo cuidadas, o que contribui para que o ser humano seja atendido de forma integral, solidária, humanizada e ética.

\section{Considerações finais}

A realização deste estudo possibilitou uma melhor compreensão acerca da valorização da espiritualidade na educação popular em saúde desenvolvida no contexto da atenção básica.

Durante o seu desenvolvimento, percebemos que ainda estamos aprendendo a entrar em contato com a dimensão espiritual do ser humano em nossa prática diária do cuidado em saúde. Sem dúvida, esse é um tema pouco debatido na formação universitária em saúde, ainda voltada ao modelo biológico, que prioriza a cura do corpo e a medicalização, em detrimento de um cuidado que extrapole essa dimensão e em que se perceba o ser humano sempre de forma holística. Considerando os aspectos aqui expostos, as academias devem priorizar a temática espiritualidade em seus currículos, permitindo que o futuro profissional adquira mais conhecimentos com vistas a melhor se preparar para a prática cotidiana do cuidar.

Essa prática, desenvolvida através da educação popular em saúde na atenção básica, tem sido um grande manancial de possibilidades, visto que, nesses locais, os profissionais das equipes de saúde da família entram em contato com todas as peculiaridades dos indivíduos, da família e da comunidade sob seus cuidados, razão por que devem procurar percebêlos tanto em suas necessidades biológicas quanto nas que dizem respeito aos campos psicológico, social e espiritual, respeitando as suas crenças, seus valores, sua cultura, seu próprio modo de ser e de viver.

Entendemos que a espiritualidade, na prática da educação popular em saúde, é uma força capaz de transformar o ser humano, ajudando-o a enfrentar as dificuldades da vida, como também a doença, com otimismo e esperança. Através da educação popular em saúde, o profissional vai criando vínculos com a comunidade e, aos poucos, encontrando meios de ajudá-la. Quando o indivíduo está doente, ele e sua família podem encontrar-se mais fragilizados e, portanto, geralmente, mais receptivos à atenção oferecida pelo profissional. Como refere Smake (2006), algo especial ocorre quando o profissional se permite, através de sua vontade, entrar em contato com a necessidade espiritual do outro ser. Esse encontro de almas gera um campo de forças capazes de intervir terapeuticamente e de cuidar.

Entretanto, para que esse profissional consiga perceber a subjetividade, a espiritualidade do outro, é preciso ter consciência de que também é um ser biopsicossocial e espiritual, que precisa se autoconhecer, autodescobrir-se e, sobretudo, aprender a desenvolver a sua espiritualidade. Logo, ele se sentirá mais apto a ajudar o outro a conviver com os problemas que o envolvem de maneira satisfatória. Como afirma Vasconcelos (2006), o desenvolvimento da espiritualidade permite ao profissional da área de saúde integrar em si as dimensões racional, sensitiva, afetiva e intuitiva, as quais permitirão mais proximidade com a pessoa sob seus cuidados e melhores condições de lidar com as situações de crise que a envolvem.

Valorizar a dimensão espiritual pode ser considerado muito importante para o profissional de saúde, tanto em benefício próprio, no âmbito pessoal, quanto em contato com o seu trabalho, uma vez que este envolve, em seu cotidiano, aspectos relacionados à vida e à morte. Assim, procurar entrar em contato com a sua espiritualidade, com o íntimo de seu ser, diariamente, é uma forma de estar mais atento, mais intuitivo e mais sensível diante da dor e do sofrimento da pessoa que se encontra sob os seus cuidados e que precisa ser percebida, também, em suas necessidades espirituais.

Enfim, como alude Wong-Un (2006), no mundo do profissional de saúde comunitária ou familiar, que se coloca do lado da maioria pobre do mundo, há imensas possibilidades de transformação interior e social que são perpassadas pela dimensão da espiritualidade. Afinal, todo processo de humanização, criação de vínculo e de integralidade em saúde é realizado por "sujeitos que queremos sensíveis, críticos, questionadores, criativos... radicalmente humanos. Enfim, plenos de poesia e de espiritualidade".

Esperamos que a realização deste estudo abra novos horizontes em relação à valorização da espiritualidade no cuidado em saúde, desenvolvido na atenção básica, em especial, através das práticas de educação popular em saúde, para proporcionar reflexões sobre a temática e suscitar a realização de outros trabalhos que tratem desse tema. 


\section{Referências bibliográficas}

BOFF, L. Espírito e saúde. In: LIMA, L.M.A. (Org.). Espírito na saúde. Petrópolis: Vozes, 1997. p.21-28.

BOFF, L. Espiritualidade: um caminho de transformação. 6. ed. Rio de Janeiro: Sextante, 2001. 94p.

BOFF, L. Tempo de transcendência: o ser humano como um projeto infinito. Rio de Janeiro: Sextante, 2000. 93p.

BRASIL, Ministério da Saúde. Atenção básica e a saúde da família. Brasília: Ministério da Saúde, 2004. Disponível em: <http://dtr2004.saude.gov.br/dab/atencaobasica.php>. Acesso em: 5 abr. 2007.

BRASIL, Ministério da Saúde. Comitê Nacional de Educação Popular em Saúde (CNEPS). Brasília, 2009.

BRASIL, Ministério da Saúde. Secretaria de Atenção à Saúde. Departamento de Atenção Básica. Política Nacional de Atenção Básica. Brasília: Ministério da Saúde, 2006.

CAMARGO JR., K.R. Biomedicina, saber e ciência: uma abordagem crítica. São Paulo: Hucitec, 2003.195p.

CAPRA, F. O ponto de mutação. 22. ed. São Paulo: Cultrix 2001. 445 p.

FERREIRA, A. B. H. Dicionário eletrônico: século XXI. Versão 3.0. 2006a.

FERREIRA, D.S.A. Experiências que marcam. In:VASCONCELOS, E.M; FROTA, L.C; SIMON, E. (Orgs.). Perplexidade na universidade: vivências nos cursos de saúde. São Paulo: Hucitec, 2006b. p.57-64.

FREIRE, P. Pedagogia do oprimido. 42. ed. Rio de Janeiro: Paz e terra, 2005. 213p.

GUEDES, C.R.; NOGUEIRA, M.I.; CAMARGO JR., K.R. A subjetividade como anomalia: contribuições epistemológicas para a crítica do modelo biomédico. Ciência e Saúde Coletiva, v. 11, n.4, p. 1093-1103, 2006.

HUF, D.D. A face oculta do cuidar: reflexões sobre a assistência espiritual em enfermagem. Rio de Janeiro: Mondrian, 2002. 205p.

KOENIG, H.G. Espiritualidade no cuidado com o paciente: por que, como, quando e o quê. Tradução Giovana Campos. São Paulo: Editora Jornalística Ltda, 2005. 140p.

KOENIG, H.G. Religião, espiritualidade e psiquiatria: uma nova era na atenção à saúde mental. Revista de Psiquiatria Clínica, v.34, s. 1, p.5-7, 2007.
LELOUP, J.Y.; HENNEZEL, M. A arte de morrer: tradições religiosas e espiritualidade humanísta diante da morte na atualidade. 6. ed. Petrópolis: Vozes, 2003. 143p.

MOREIRA-ALMEIDA, A. Espiritualidade e saúde: passado e futuro de uma relação controversa e desafiadora. Revista de Psiquiatria Clínica, v.34, s. 1, p.3-4, 2007.

PAIVA, V. História da educação popular no Brasil: educação popular e educação de jovens e adultos. 6. ed. São Paulo: Loyola, 2003. 527p.

PEREIRA, P. Quando o melhor remédio é a fé. Revista Tudo. n.88, p.24-29, 2002.

PESSINI, L. Espiritualidade e a arte de cuidar em saúde. In: ANGERAMIN-CAMON, V.A. (Org.). Espiritualidade e prática clínica. São Paulo: Pioneira Thomson Learning, 2004. p.39-84.

SMEKE, E.L.M. Espiritualidade e atenção primária à saúde: contribuições para a prática cotidiana. In: VASCONCELOS, E.M. (Org.). Espiritualidade no trabalho em saúde. São Paulo: Hucitec, 2006. p.296-324.

SOARES, M.S.; LIMA, C.B. Grito de dor e canção de amor: visão humanística da AIDS na perspectiva da espiritualidade. João Pessoa: Universitária/UFPB, 2005. 170p.

SOUSA, M.R.C.; BATISTA, P.S.S. Climatério e espiritualidade: vivência de mulheres. 2006. 54f. Trabalho de Conclusão de Curso - Centro de Ciências da Saúde, Universidade Federal da Paraíba, João Pessoa, 2006.

VALLA, V.V. A vida religiosa como estratégia das classes populares na América Latina de superação do impasse que marca suas vidas. In: VASCONCELOS, E.M (Org.). Espiritualidade no trabalho em saúde. São Paulo: Hucitec, 2006. p.265-295.

VALLA, V.V. Apoio social e saúde: buscando compreender a fala das classes populares. In: COSTA, M.V. (Org.). Educação popular hoje. São Paulo: Loyola, 1998. p.151-180.

VASCONCELOS, E.M. A espiritualidade na educação popular em saúde. Revista APS, v.7, n.2, p.110-118, 2004.

VASCONCELOS, E.M. A espiritualidade no cuidado e na educação em saúde. In: VASCONCELOS, E. M. (Org.). Espiritualidade no trabalho em saúde. São Paulo: Hucitec, 2006. p.9-162.

VASCONCELOS, E.M. Educação popular nos serviços de saúde. 3. ed. São Paulo: Hucitec, 1997. 167p.

VASCONCELOS, E.M. Redefinindo as práticas de saúde 
a partir da educação popular nos serviços de saúde. In: VASCONCELOS, E. M. (Org.). A saúde nas palavras e nos gestos: reflexões da rede de educação popular e saúde. São Paulo: Hucitec, 2001.p.11-20.
WONG-UN, J.A. O sopro da poesia: revelar, criar, experimentar e fazer saúde comunitária. In: VASCONCELOS, E.M (Org.). Espiritualidade no trabalho em saúde. São Paulo: Hucitec, 2006. p. 198-222. 